\title{
UAV IMAGING AT RGB FOR CROP CONDITION MONITORING
}

\author{
T. Choroś ${ }^{1}$, T. Oberski ${ }^{1}$, T. Kogut ${ }^{1}$ \\ ${ }^{1}$ Dept. of Geoinformatics, Koszalin University of Technology, Sniadeckich 2, 75-453 Koszalin, Poland- \\ t.choros@wp.pl, \{tomasz.obrski; tomasz.kogut\}@tu.koszalin.pl
}

KEY WORDS: UAV imaging, corp condition, monitoring, vegetation index

\begin{abstract}
:
Modern techniques such as precision agriculture tasks are provided to intentional fertilization, pesticide dosing or simply watering the crops. These tasks need to be continuously monitored. One of known method for analyzing the crops conditions is calculating the vegetation indexes. This paper focuses on purpose of using images made with UAV equipped with ordinary non-metric digital RGB camera. The methods had been taken revealed easy to use and cost effective. We present an experiment which attend to distinguish different crops conditions on two test fields sowed with wheat and rape. For this purpose, two different RGB based vegetation indexes were analyzed. The results of calculated indexes shown how crops differs in each stage of vegetation. During the first stage (germinating) the plants are green and average TGI is low. It increases at second stage (flowering) because of plant flowers, which partly cover the leaves. At last stage (ripening) TGI decreases, so plants are still green but starting to dry and change their color.
\end{abstract}

\section{INTRODUCTION}

Due to increasing crop production efforts many modern activities are involved. Modern techniques such as precision agriculture tasks are provided to intentional fertilization, pesticide dosing or simply watering the crops. These tasks need to be continuously monitored. One of known method for analyzing the crops conditions is calculating the vegetation indexes. They are usually based on combination of visible and infrared bands. Recording crop spectral answer is important for further analyses. Therefore, such actions should be easy to use, cost effective and give reliable measurements. While infrared imaging needs specialized equipment, RGB imaging could be useful as well. This paper focuses on purpose of using images made with UAV equipped with ordinary non-metric digital RGB camera. The methods had been taken revealed easy to use and cost effective.

It was indicated that digital cameras might be used to acquire very-high spatial resolution data to estimate chlorophyll content (Hunt et al., 2011). Calculating of RGB bands combination results vegetation condition indexes creation. At least two of vegetation indexes could be used to give the valuable answer. The TGI (Triangular Greenness Index) is decreasing with increasing leaf chlorophyll content (Hunt et al., 2013) and for that reason is suitable for plant condition indicator. VARI in general responds directly proportional to vegetation fraction which is the ratio of vegetation occupying unit area (Gitelson et al., 2002).

In this paper we present an experiment which attend to distinguish different crops conditions on two test fields sowed with wheat and rape. For this purpose, two different RGB based vegetation indexes, described in Section 2 were analyzed. We put emphasis on correct time of imaging corresponding with plant grow stages. In each particular grow stage plant monitoring reveals the issues to be important for further harvesting.

\section{DATA AQUIRING AND PROCESSING}

\subsection{Plant grow stages}

Wheat is one of the most common cereals in the world. Wheat cultivation stands out from other cereals with high demands on both soil and type of agrotechnology. Ensuring of correct adjustment and provision of several basic soil parameters, such as chemical and mineral ingredients, physical and biological specification and its mechanical fraction is associated with the obtaining high grain yield. Therefore, soil cultivation for preparing the field for sowing is reveals as important aspect of wheat yield. Another important aspect is to provide nourishment components, watering and crop protection products. Rapeseed is one of the most important oilseeds. More than $40 \%$ of seeds weight is oil, and the rest by-product of rapeseed oil extraction has a high protein content. There are several factors responsible for the proper development of rape, including the type of forecrop, the type of soil with its ingredients content and the cultivation techniques. The basis for assessing the possibility of rapeseed development is mainly the value of crop forecrop. It is a factor consisting of such parameters as: the type of root system and depth of root penetration, the amount and type of remaining crop residues or amount soil shading (Jajor, Mrówczyński, 2013). Generally, plant development during the growing season could be described on the $\mathrm{BBCH}$ standardized scale. The BBCH scale (ger. Bundesanstalt, Bundessortenamt und $\boldsymbol{C H}$ emische) (Hack et al.,1992) is used in EU for identifying phytophenological phases of crop plants. The BBCH series of scales has been developed for many monocotyledonous and dicotyledonous plant species. Due to possibilities of detailed application of plant development it is used in many scientific disciplines (physiology, phytopathology, entomology, plant breeding) and in agriculture (pesticide use time, pollination, agricultural diets). The $\mathrm{BBCH}$ scale uses a decimal code system that describes the primary (Table 1) and secondary wheat (Witzenberger et al., 1989; Lancashire et al., 1991) and rape (Weber and Bleiholder, 1990; Lancashire et al., 1991) development.

\begin{tabular}{|l|l|}
\hline $\begin{array}{l}\text { Principal growth stage of } \\
\text { wheat }\end{array}$ & $\begin{array}{l}\text { Principal growth stage of } \\
\text { rape }\end{array}$ \\
\hline 0: Germination & 0: Germination \\
\hline 1: Leaf development & 1: Leaf development \\
\hline 2: Tillering & 2: Formation of side shoots \\
\hline 3: Stem elongation & 3: Stem elongation \\
\hline 4: Booting & - \\
\hline $\begin{array}{l}\text { 5: Inflorescence emergence, } \\
\text { heading }\end{array}$ & 5: Inflorescence emergence \\
\hline
\end{tabular}




\begin{tabular}{|l|l|}
\hline 6: Flowering, anthesis & 6: Flowering \\
\hline 7: Development of fruit & 7: Development of fruit \\
\hline 8: Ripening & 8: Ripening \\
\hline 9: Senescence & 9: Senescence \\
\hline
\end{tabular}

Table 1 - BBCH codes for wheat and rape primary grow stages

\subsection{Imaging of crops}

The purpose of the work had been to check if RGB imaging is useful for monitoring plants condition. The object of monitoring are two test fields located in Northern-West part of Poland (Fig.1), (16.25E, 54.15W) sown with wheat and rape. Field area of monitored crops is 12 hectares.

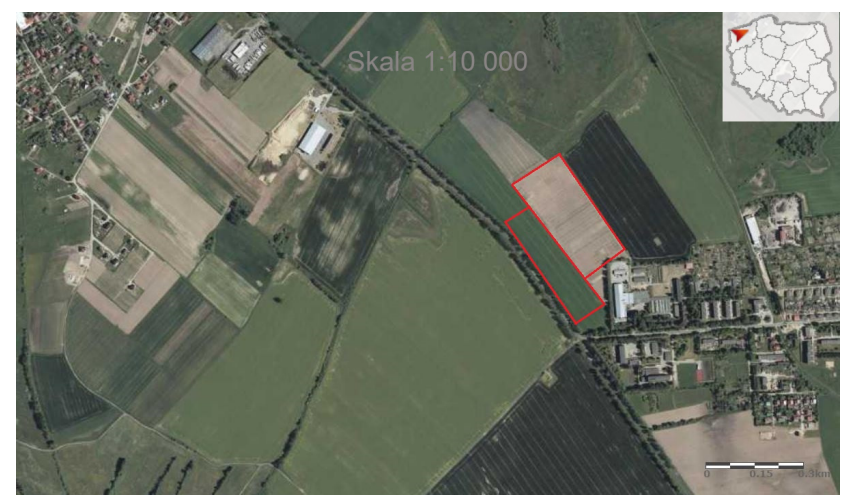

Figure 1 - Orthoimage of test area

Several imaging missions had been made using UAV DJI Phantom 4 Advanced equipped with standard RGB camera. The time of imaging was chosen in a way to capture distinctive stages of plant growth. Several series of high-resolution images were captured during the flight missions. The time of flight missions providing were corresponding to chosen distinctive crop stages. It allowed to acquire information about plants during germinating, flowering and ripening (Tab. 2).

\begin{tabular}{|c|c|c|}
\hline Crop type & Date of acquiring & Plant growing stage \\
\hline \multirow{3}{*}{ wheat } & 2019.04 .04 & 0: germinating \\
\cline { 2 - 3 } & 2019.04 .25 & 6: flowering \\
\cline { 2 - 3 } & 2019.06 .14 & 8: ripening \\
\hline \multirow{3}{*}{ rape } & 2019.04 .04 & 0: germinating \\
\cline { 2 - 3 } & 2019.05 .07 & 6: flowering \\
\cline { 2 - 3 } & 2019.06 .10 & 8: ripening \\
\hline
\end{tabular}

Table 2. Flight mission time

Due to high accuracy requirement control points were assigned in a field. After marking their coordinates were measured with GPS Leica CS10. They were used as ground control points for accuracy assessment during ortorectification process. Orthorectification of taken images were made using Pix4D software. Six orhtophotomaps (3 for each type of crop) were compiled to calculate vegetation indexes.

\subsection{Postprocessing and calculations}

The images had been used to gather the view of plants chlorophyll sensitivity (TGI) and leaf coverage (VARI). Taken images were postprocessed to gain orthomosaics and then disassembled to single RGB bands. These RGB bands were used to calculate vegetation indexes (TGI and VARI) according to formulas (Form.1-2) (https://support.pix4d.com/hc/enus/articles/360000891623-Generate-a-vegetation-index).

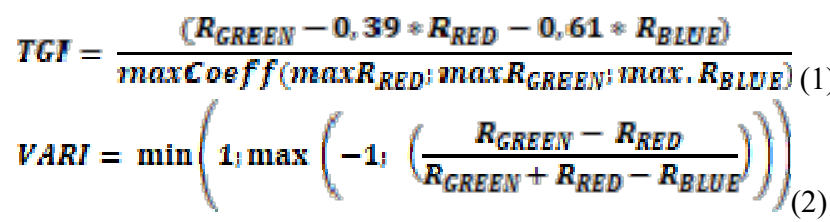

In result 12 pseudo colored maps of indexes had been obtained (Fig. 2-5)

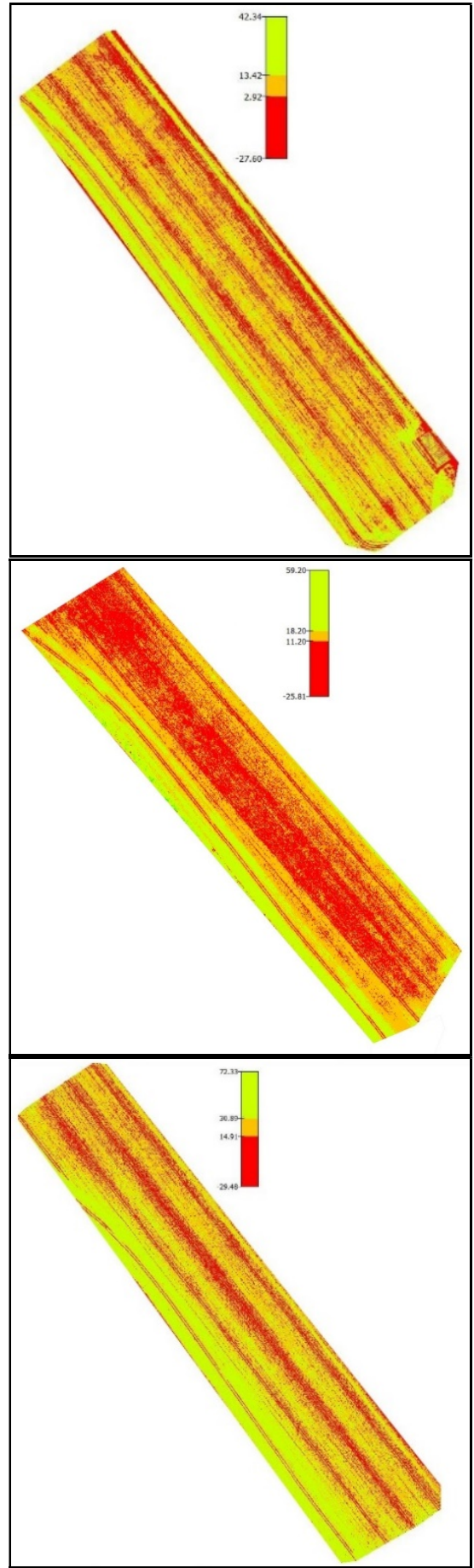

Figure 2 - TGI maps for wheat crops (A - germinating, B flowering, $\mathrm{C}$ - ripening) 


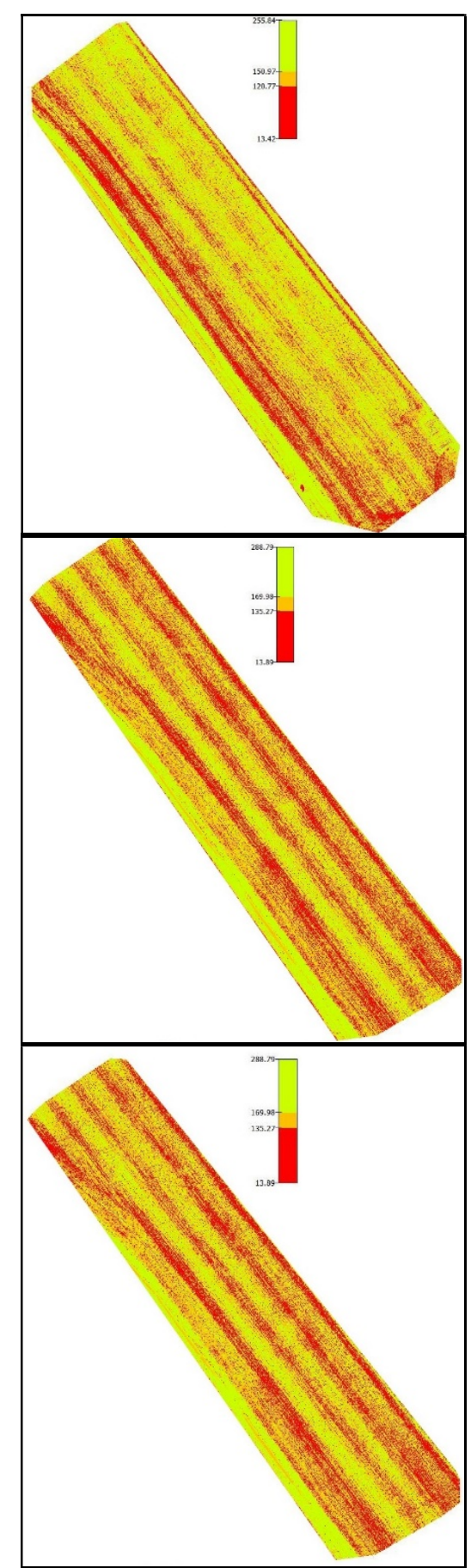

Figure 3 - VARI maps for wheat crops (A - germinating, B flowering, $\mathrm{C}$ - ripening)

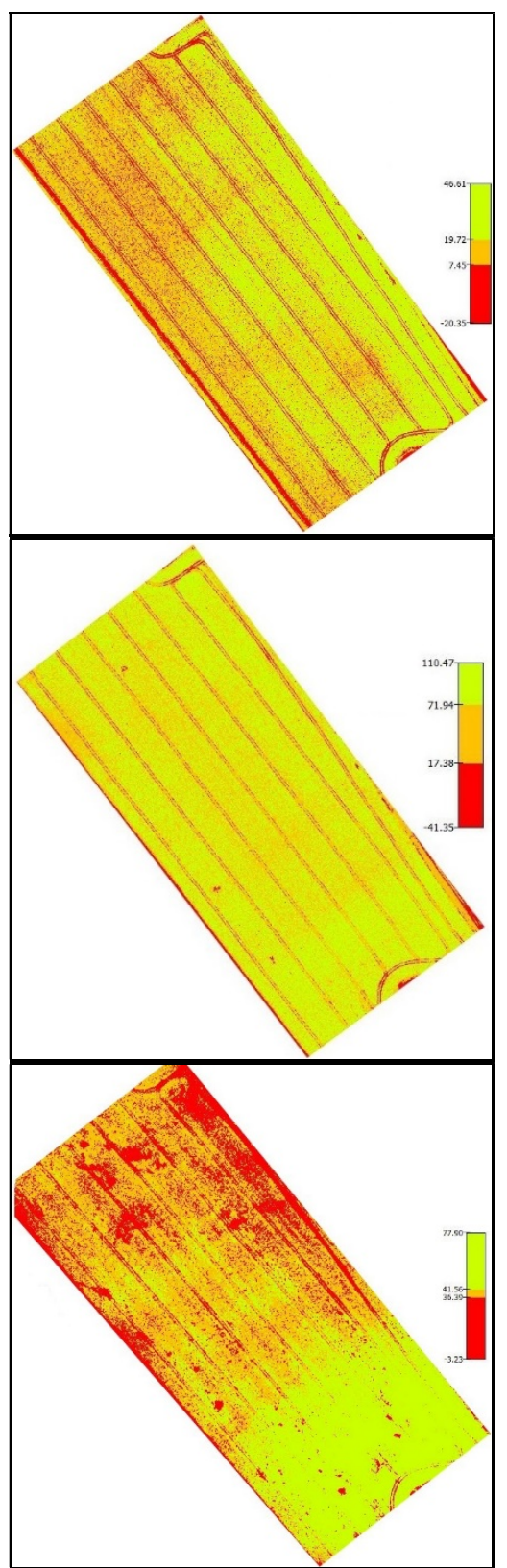

Figure 4 - TGI maps for rape crops (A - germinating, B flowering, $\mathrm{C}$ - ripening) 


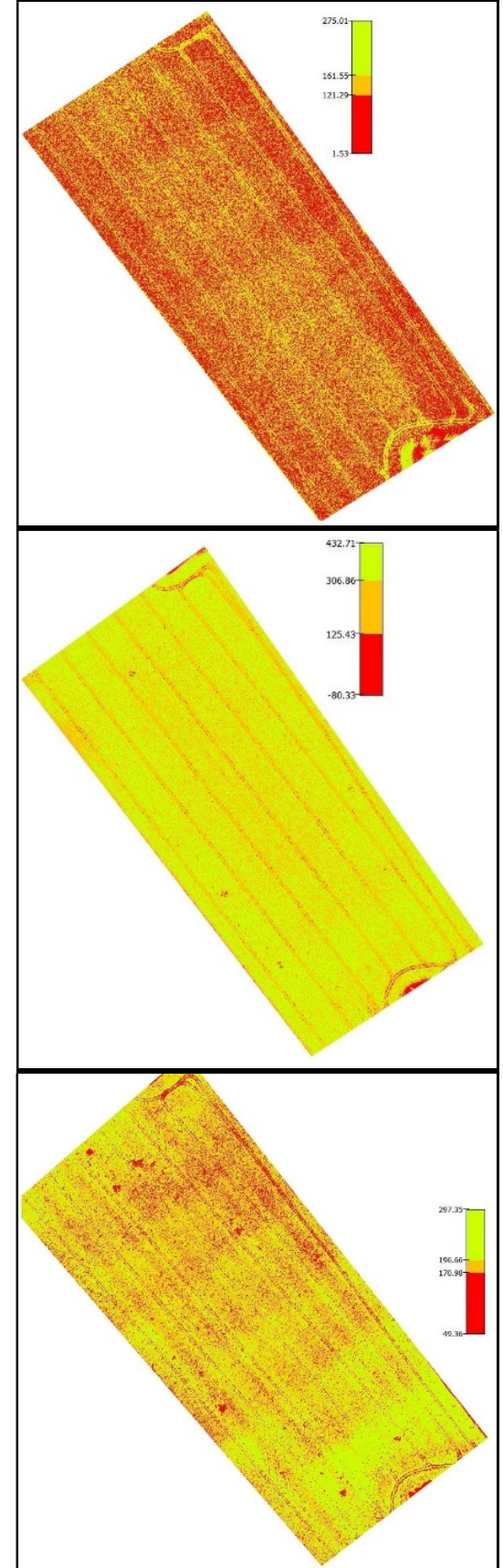

Figure 5 - VARI maps for rape crops (A - germinating, B flowering, $\mathrm{C}-$ ripening)

The average values of TGI (Fig. 2, Fig. 3) and VARI (Fig. 4, Fig. 5) were calculated for each map to be compared with plant growth stages.

\section{DISCUSSION}

The results of calculated indexes shown how crops differs in each stage of vegetation. Considering wheat and rape crops it is claimed that depending on chlorophyll content TGI values are changing. During the first stage (germinating) the plants are green and average TGI is low (value 7.37, figure (6)). It increases (value 21.44) at second stage (flowering) because of plant flowers, which partly cover the leaves. At last stage (ripening) TGI decreases (value 16.70), so plants are still green but starting to dry and change their color. The TGI values calculated for rape crops figure (7) varies correspondingly 13.13 at germinating, 44.55 at flowering and 37.34 at ripening stages. According to VARI values (figure (8) (9)) it reveals relationship between growth of plants to index values. Generally, it increases during time of crop growing but in these tasks some anomalies had been noticed. It has to be noticed in case of wheat crops VARI value is lower during ripening than at germinating. That is because some plants had died back after flowering so there are a few bare soil places in field area. In case of rape crops VARI increases as expected, but at stage of flowering its value reaches maximum. It not obvious and that result should be considered as error because flowering is so intensive that acquired images are so yellow and cannot be compared to other ones.

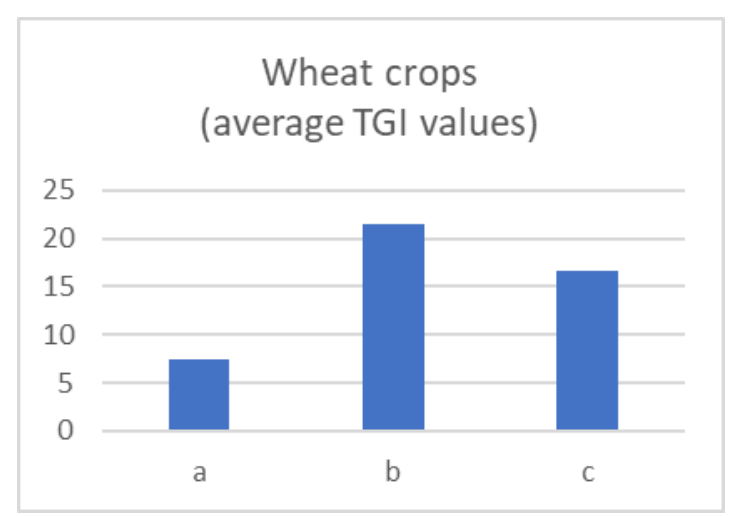

Figure 6 - chart of TGI for wheat crops; a- wheat germinating, b-wheat flowering, c-wheat ripening.

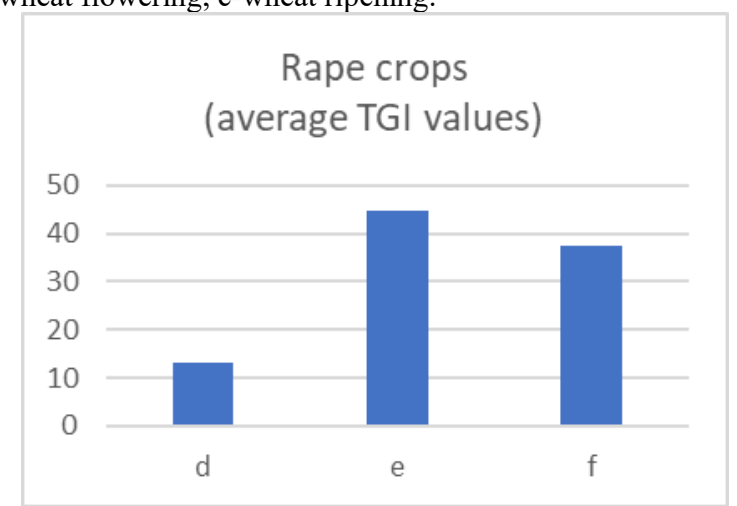

Figure 7- chart of TGI for rape crops; d- rape germinating, erape flowering, f- rape ripening.

\section{Wheat crops (average VARI values)}

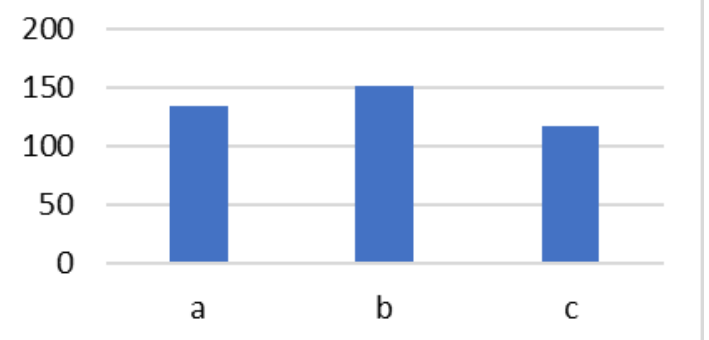

Figure 8- chart of VARI for wheat crops; a- wheat germinating, b-wheat flowering, c-wheat ripening. 


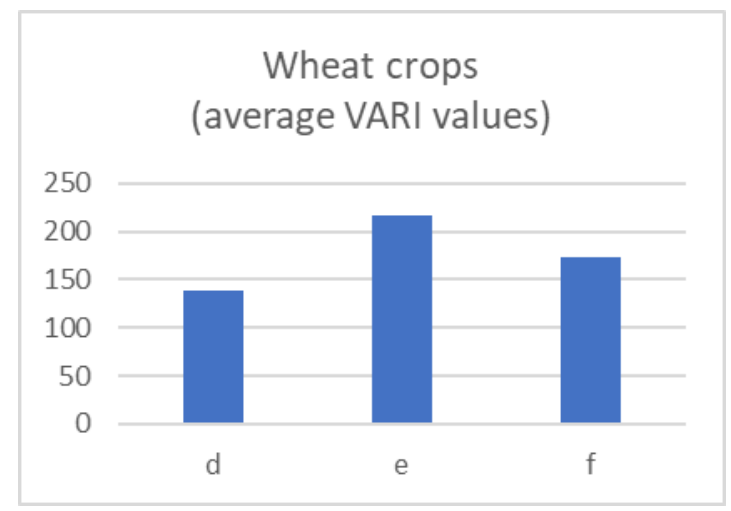

Figure 9 - chart of VARI for rape crops; d- rape germinating, erape flowering, f- rape ripening.

\section{CONCLUSION}

This experiment showed possibilities of RGB imaging using UAV equipped with standard RGB camera. This kind of equipment is low-cost, easy to operate and could be applied as many times as need is. The method seems to be quick, easy to make and quite reliable for crop monitoring. Despite the information of crops condition is basic it delivers some cues for farmers to instigate argotechnical actions which benefit prospective crop yelds. The imaging timetable should be corelated to plant grow stages. The the $\mathrm{BBCH}$ standardized scale revealed to be helpful with planning time of UAV flight mission time.

\section{REFERENCES}

Gitelson A. A., Stark R., Grits. U, Rundquist D., Kaufman Y., Derry D., 2002, Vegetation and soil lines in visible spectral space: a concept and technique for remote estimation of vegetation fraction, Int. J. Remote Sensing, vol. 23, no. 13, $2537-2562$

Hack, H., Gall H., Klemke Th., Klose R., Meier U., Stauss R., Witzenberger P., 1993: Scale for phenological growth stages of potato ( Solanum tuberosum L.). Proceedings der 12. Dreijahrestagung der Euro. Gesell. für Kartoffelforschung Paris, 153-154.

Hunt E.R. Jr., Daughtry C. S. T. Eitel J. U. H., Long D. S.,2011, Remote Sensing Leaf Chlorophyll Content Using a Visible Band Index, Soil Fertility \& Crop Nutrition,

Jajor E., Mrówczyński M.: Metodyka integrowanej ochrony rzepaku ozimego i jarego dla producentów. Instytut Ochrony Roślin. Państwowy Instytut Badawczy, Poznań 2013

Lancashire, P. D., Bleiholder, H., Boom, T. V. D., Langelüddeke, P., Stauss, R., Weber, E., Witzenberger, A. (1991): A uniform decimal code for growth stages of crops and weeds. Ann. Appl. Biol. 119, 561-601.

E. Raymond Hunt E. R. Jr., Doraiswamya P. C., McMurtreya J. E., Daughtrya C. S. T., Perry E. M., Akhmedov B., 2013, A visible band index for remote sensing leaf chlorophyll content at the canopy scale, International Journal of Applied Earth Observation and Geoinformation, Volume 21, Pages 103-112

Weber E., Bleiholder H., Explanations of the BBCH Decimal Codes for the Growth Stages of Maize, Rape, Faba Beans,
Sunflowers and Peas-With Illustrations, 42, Gesunde Pflanzen (1990), pp. 308-321

Witzenberger, A., Vanden, B. T. \& Hack, H. Explanations of the $\mathrm{BBCH}$ decimal code for the growth stages of cerals - with illustrations. Gesunde Pflanzen 41, 384-388 (1989)

https://support.pix4d.com/hc/en-us/articles/360000891623Generate-a-vegetation-index, 2020-04-29 